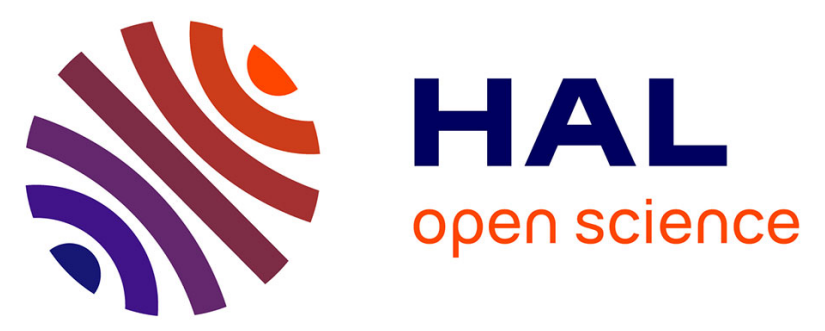

\title{
New challenges and directions toward nanoscale control of rare-earth properties in silica amplifying optical fibres
}

Wilfried Blanc, Bernard Dussardier

\section{To cite this version:}

Wilfried Blanc, Bernard Dussardier. New challenges and directions toward nanoscale control of rareearth properties in silica amplifying optical fibres. Photonics 2014 - 12th International Conference on Fiber Optics and Photonics (Photonics 2014, OSA)-book of abstracts, Indian Institue of Technology Kharagpur, and Optical Society of America, Dec 2014, Kharagpur, India. pp.S3A.1, 10.1364/PHOTONICS.2014.S3A.1 . hal-01146572

\section{HAL Id: hal-01146572 \\ https://hal.science/hal-01146572}

Submitted on 28 Apr 2015

HAL is a multi-disciplinary open access archive for the deposit and dissemination of scientific research documents, whether they are published or not. The documents may come from teaching and research institutions in France or abroad, or from public or private research centers.
L'archive ouverte pluridisciplinaire HAL, est destinée au dépôt et à la diffusion de documents scientifiques de niveau recherche, publiés ou non, émanant des établissements d'enseignement et de recherche français ou étrangers, des laboratoires publics ou privés. 


\title{
New challenges and directions toward nanoscale control of rare-earth properties in silica amplifying optical fibres.
}

\author{
W. Blanc and B. Dussardier \\ Univ. Nice Sophia Antipolis, CNRS, LPMC, UMR 7336, 06100 Nice, France \\ bernard.dussardier@unice.fr
}

\begin{abstract}
We review our recent progress in the characterization of the embedding of rare-earth elements in nanometer-scale particles or phase-separated glassy regions within the core of silicabased optical fibres, and discuss future directions.

OCIS codes: (060.2290) Fiber materials; (060.2410) Fibers, erbium; (060.2320) Fiber optics amplifiers and oscillators; (060.3510) Lasers, fiber; (160.5690) Rare-earth-doped materials.
\end{abstract}

\section{Introduction}

Developing of new rare-earth (RE)-doped optical fibres for power amplifiers and lasers requires continuous improvements of the fibre spectroscopic properties, besides optimizing of the device compacity and economical efficiency. Silica glass as a host material for fibres has proved to be very attractive, because this glass has a high optical damage threshold, a relatively low non-linear coefficient, low loss and low cost. However, silica has a low solubility to rare-earth (RE) elements. Also some potential applications of RE-doped silica-based fibres suffer from limitations in terms of spectroscopic properties resulting from clustering or inappropriate local environment. This concerns many characteristics like gain, quantum efficiency, resistance to spectral hole burning, photodarkening, energy-transfers, etc. One route of interest consists of using silica as a supporting mechanical host for the fibre optical waveguide, while embedding RE-ions (or other active ions like transition metals) within dielectric nanoparticles (DNP). The fibre core material is called 'Transparent Glass Ceramics' (TGC) for convenience [1], although the DNP may also be amorphous, such as those obtained by phase separation [2].

The DNP composition and structure are different compared to those of silica. The spectroscopic properties of RE-ions embedded within DNP are expected to be noticeably different from those in silica. One expects to control some spectroscopic properties to a certain level, depending on the sought application : shaping/smoothing of gain spectrum by "amorphization", inducing high transition strengths by crystallisation, modifying the spectral holeburning in gain curves, or the photodarkening and/or radiodarkening behaviour by changing the local environment of RE ions, or enhancing specific non-radiative energy transfers by increasing the local RE concentration within DNPs. Also the DNP mean diameter and the DNP interparticulate distance should be small enough to minimize scattering loss down to an acceptable value for the desired application. For lasers and optical amplifiers, a background loss less than $0.1 \mathrm{~dB} / \mathrm{m}$ is often suggested.

Many challenges concern the manufacture and the characteirzation of amplifying TGC-core fibres :

- $\quad$ are the DNP stable, or dissolve, or change their nature through the fibre drawing stage $\left(>2000^{\circ} \mathrm{C}\right)$ ?

- $\quad$ is the scattering induced loss acceptable ?

- do the desired spectroscopic properties achieved in the final fibre?

- what specific tools for characterizing the composition and structure of dielectric nanoobjects embedded in glass?

- $\quad$ is the modeling of the DNP growth possible, mimicking the dynamical fabrication process?

- can we link the nanoscale material characteristics and the macroscopic optical properties?

Several years ago, our team has lauched into the study of RE-doped TGC prepared by spontaneous phase separation using the MCVD and solution doping techniques. In next section, we review techniques to obtain REdoped TGC cores in fibres, then we briefly report recent progress in the material and spectroscopic characterization TGC optical fibres.

\section{Manufacture and characterization of fibres with TGC core}

Usually, a TGC is produced by preparing some homogenous glass (including in the shape of a fibre), and then by submitting it to heat treatments (ceramming stage) to induce nucleation and growth of DNP. There are only few reports on RE-doped TGC singlemode fibres produced along this principle. They used mixed oxides [3], or mixed oxyfluorides [4], both with a subsequent ceramming stage applied onto the fibre. These TGC have a low melting point, are prone to optical damage and the ceramming degrades the fibre strength. 
Techniques based on CVD are investigated because they would produce cost-effective TGC-core fibres, with potentially low background loss. Two main routes are investigated to obtain RE-doped DNP. The first is based on the so-called "slurry doping method". It consist of synthesizing DNP in a liquid suspension by some chemical process, and then incorporating them as it is done for the solution doping method [5]. The second route consists in preparing a porous core layer (for example by MCVD) and use the solution doping (SD) technique or a gas phase technique, to introduce the chemicals that will cause the spontaneous generation of DNP within the core material during the preform preparation and/or during the fibre drawing step. We have first proposed this principle using MCVD and the solution doping technique (MCVD+SD) [6]. It is based on the spontaneous phase separation principle : silicate systems can exhibit strong and stable immiscibility when they contain oxides of divalent metals (MO) [2]. Under heat, the glass decomposes into a silica-rich phase, and a MO-rich phase forming DNP. Three key advantages of this process are: (i) DNP are grown in situ, (ii) there is no need (and associated risks) of DNP manipulation and (iii) the process benefits from the typical compositional control and purity of the CVD techniques.

Some reports use MCVD+ SD with very complex doping solution (for instance, containing Yttrium, Barium, Lithium and RE ions) : although it is not clear whether RE ions are embedded in DNP, interesting results in fibre hardening against photodarkening were attributed to the presence of DNP in the fibre [7]. Because of the complexity of the fondamental phenomena in action and of the thermal process in manufacturing TGC fibres by MCVD, it is necessary to study a relatively simple glass system and perform advances characterizations. We have chosen the alkaline-earth elements series as phase separating agents in order to study the DNP growth dynamics, the resulting composition and structure, and their effects on the spectroscopic properties of the RE-doped TGC fibres. Once the process is better understood, more complex systems may be implemented with applications in mind.

We have implemented this in the alkaline-earth series $(\mathrm{Mg}, \mathrm{Ca}, \mathrm{Sr})$ using $\mathrm{MCVD}+\mathrm{SD}[6,8]$. We also demonstrated without ambiguity that the DNP (grown during the fabrication of the preform) were successfully preserved during the drawing stage [9], and that most or all RE ions where embedded within DNP, depending on the process parameters [10]. We had reported that one critical parameter is the concentration of alkaline-earth element in the soaking solution. First, the DNP dimension is sensitive to the amount of available alkaline elements. Second, a great broadening of the $1.55-\mu \mathrm{m} \mathrm{Er}^{3+}$ fluorescence happens when the alkaline-earth concentration is high in the solution (Fig. 1).

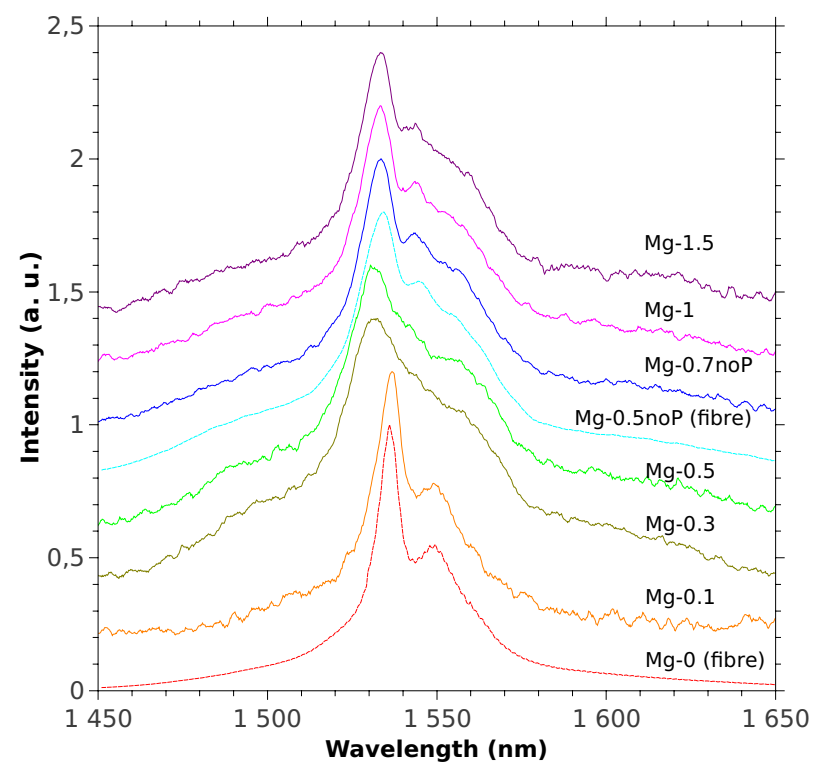

Fig. 1: Room temperature emission from Er- and Mg-codoped preforms and fibres $(M g-0$ and $M g-0.5 n o P)$ under 980 -nm excitation. From bottom to top, the concentration in $\mathrm{Mg}$ is increased in the doping solution (from [11])

\section{Future directions}

We give here some directions under investigation. Details will be communicated at the conference. We have recently shown that, using the MCVD + SD process the concentration of the phase separating agent (Magnesium) had a great influence on the DNP composition, the average DNP dimension and the emission properties of $\mathrm{Er}^{3+}$ (Fig. 1) $[11,12]$. The modifications of the $\mathrm{Er}^{3+}$ ion spectroscopy in $\mathrm{Mg}$-silicate DNP were linked to the close environment of 
$\mathrm{Er}^{3+}$ ions, as measured using EXAFS (Extended X-rays Absorption Fine Spectroscopy) [11]. We have also investigated $\mathrm{Er}^{3+}$-doped TGC using Atom Probe Tomography (APT). It was confirmed that $\mathrm{Er}^{3+}$ ions are also located in DNP as small as $10 \mathrm{~nm}$ [13], and that APT is a good tool for studying such TGC in optical fibres.

MCVD+SD is a good process to study phase separation and TGC synthesis in silica-based fibres. However, it has some limitations. Alternative methods of producing TGC are under investigation. One is a doping technique using gas precursors of $\mathrm{Mg}$ and $\mathrm{Er}$ to dope MCVD preforms. In this case the relative concentration (viz. silica) of modifiers and phase separating agents is in principle not limited. An $\mathrm{Er}^{3+}$-highly doped TGC-core fibre with a background loss as low as $0.6 \mathrm{~dB} / \mathrm{m}$ was obtained.

Oxyfluoride TGC are interesting for the implementation of certain RE optical transitions, such as $1.47 \mu \mathrm{m}$ in $\mathrm{Tm}^{3+}$. MCVD+SD does not seem adapted to dope with fluorinated compounds, because of the strong volatility of fluorine. Instead, we have applied the so-called "slurry method" to incorporate $\mathrm{LaF}_{3} \mathrm{DNP}$ doped with RE ions. Although, most or all fluorine was vaporized during the high temperature proces, small and numerous DNP were stabilized in the fibre core. That induced background loss is less than $0.1 \mathrm{~dB} / \mathrm{m}$. Further, interesting spectroscopic features are observed in the fibres, such as the increasing of the lifetime of the ${ }^{3} \mathrm{H}_{4}$ energy level of $\mathrm{Tm}^{3+}(70 \mu \mathrm{s}$ instead of $\sim 14 \mu$ s in silica) [14].

Finally, the numerical study of the growth of DNP during the melting and quenching of a $\mathrm{MgO}-\mathrm{SiO}_{2}$ mixture is under investigation using Molecular Dynamics principles. It is also found that $\mathrm{Mg}$ is responsible for the phase separation in the glass, and that the DNP is a MgO-rich phase silicate phase.

\section{References}

[1] M. Clara Gonçalves, L. F. Santos and R. M. Almeida, “Rare-earth-doped transparent glass ceramics,” C. R. Chimie 5, 845-854 (2002).

[2] J. Zarzycki, Glasses and the vitreous state (Cambridge University Press, 1991).

[3] B.N. Samson, L.R. Pinckney, J. Wang, G.H. Beall, N.F. Borrelli, "Nickel-doped nanocrystalline glass-ceramic fiber," Opt. Lett. 27, 13091311 (2002).

[4] B.N. Samson, P.A. Tick, N.F. Borrelli, "Efficient neodymium-doped glass-ceramic fiber laser and amplifier," Opt. Lett. 26, 145-147 (2001).

[5] S. Yoo, U.-C. Paek, W.-T. Han, "Development of a glass optical fiber containing $\mathrm{ZnO}-\mathrm{Al}_{2} \mathrm{O}_{3}-\mathrm{SiO}_{2}$ glass-ceramics doped with $\mathrm{Co}^{2+}$ and its optical absorption characteristics," J. Non-Cryst. Sol. 315, 180-186 (2003).

[6] F. d'Acapito, C. Maurizio, M. C. Paul, Th. S. Lee, W. Blanc, B. Dussardier, "Role of CaO addition in the local order around Erbium in $\mathrm{SiO}_{2}-\mathrm{GeO}_{2}-\mathrm{P}_{2} \mathrm{O}_{5}$ fiber performs", Materials Science and Engineering B 146, 167-170 (2008).

[7] S. Yoo, M. P. Kalita, A. J. Boyland, A. S. Webb, R. J. Standish, J. K. Sahu, M. C. Paul, S. Das, S. K. Bhadra, et M. Pal, "Ytterbium-doped $\mathrm{Y}_{2} \mathrm{O}_{3}$ nanoparticle silica optical fibers for high power fiber lasers with suppressed photodarkening," Opt. Comm. 283, 3423-3427 (2010).

[8] W. Blanc, V. Mauroy, B. Dussardier, "Erbium-doped nanoparticles in silica-based optical fibres", Int. J. Nanotech. 9 (3-7) $480-487$ (2012)

[9] W. Blanc, B. Dussardier, G. Monnom, R. Peretti, A.-M. Jurdyc, B. Jacquier, M. Foret and A. Roberts, "Erbium emission properties in nanostructured fibers," Appl. Opt. 48 (31) G119-G124 (2009).

[10] W. Blanc, C. Guillermier, B. Dussardier, "Composition of nanoparticles in optical fibers by Secondary Ion Mass Spectrometry," Opt. Mat. Exp. 2, 1504-1510 (2012).

[11] F. d' Acapito, W. Blanc and B. Dussardier, "Different $\mathrm{Er}^{3+}$ environments in Mg-based nanoparticle-doped optical fibre preforms," J. NonCryst. Sol. 401, 50-53 (2014).

[12] W. Blanc, V. Mauroy, L. Nguyen, S.N. Bhaktha, P. Sebbah, B. P. Pal and B. Dussardier, "Fabrication of Rare Earth-Doped Transparent Glass Ceramic Optical Fibers by Modified Chemical Vapor Deposition," J. Am. Ceram. Soc. 94(8) 2315-2318 (2011).

[13] W. Blanc, H. Francois-Saint-Cyr, I. Martin, P. LeCoustumer, C. Hombourger, D. Neuville, D. J. Larson, T. J. Prosa, C. Guillermier, "Erbium environment in glass-ceramics investigated by atom probe tomography", 17th International Conference on Luminescence and Optical Spectroscopy of Condensed Matter (ICL), 13-18 july 2014, Wroclaw (Poland), paper O-97.

[14] M. Vermillac, J.-F. Lupi, M. Ude, S. Trzesien, B. Dussardier, W. Blanc, O. Tottereau, Ph. Vennéguès, C. Kucera, J. Ballato, "Spectroscopic properties of $\mathrm{LaF}_{3}: \mathrm{Tm}^{3+}$ nanoparticle-doped silica optical fibers ", Specialty Optical Fibers, Advanced Photonics: OSA Optics \& Photonics Congress, Barcelona, 27-31 July 2014, Barcelona (Spain), Paper SoTh1B.4. 